\title{
New journal: Applied Water Science
}

\author{
Abdulrahman I. Alabdulaaly $\cdot$ Enrico Drioli
}

Published online: 27 November 2010

(c) The Author(s) 2010. This article is published with open access at Springerlink.com

The availability of water is a strategic factor for our quality of life, for industrial production, and for the development of agriculture. Moreover, not only water quantity is important, but also water quality. The unchecked continued growth in population, industry, agriculture and our overall standard of living has created significant water deficiency, and consequently, water stress worldwide. Not only are the traditional arid or semiarid countries suffering from water stress, but also advanced countries throughout the world, even those which enjoy relatively high rainfall.

While the careful management of natural water sources remains the primary source of fresh water, technological advances in desalination and water treatment and reuse have become fundamentally important in supporting our water needs. Such technological developments certainly provide the promise of sufficient water; however, our continued industrialization and agricultural development

\section{A. I. Alabdulaaly $(\square)$}

King Abdulaziz City for Science and Technology, P.O. Box 6086, Riyadh 11442, Saudi Arabia

e-mail: abdulaly@kacst.edu.sa

\section{E. Drioli}

Department of Chemical Engineering and Materials, University of Calabria, Via P. Bucci Cubo 42/A, 87030 Arcavacata di Rende (CS), Italy

e-mail: e.drioli@unical.it; e.drioli@itm.cnr.it

\section{E. Drioli}

Institute on Membrane Technology, ITM-CNR, c/o University of Calabria, Via P. Bucci Cubo 17/C, Arcavacata di Rende (CS), Italy

E. Drioli

WCU Energy Engineering Department, Hanyang University, WCU Energy Engineering Department, 17 Haengdang-dong, Seongdong-gu, Seoul 133-791, South Korea means that such advances need to keep abreast of old and new problems related to pollution, including those from the pharmaceutical and electronics industries, the usage of pesticides and various forms of environmental maltreatment. Of growing importance is the fact that not only water scarcity, but also the scarcity of the various metals characterizing innovative materials and innovative products for water treatment, will also become strategically important in the near future.

Therefore, an holistic approach to solve the water problem, taking into consideration all the different aspects from water availability to water purification, water distribution, water reuse and water management, is imperative and indispensable.

The central aim of the new journal Applied Water Science is to realize this strategy, covering all aspects of water science, management and engineering, offering a comprehensive overview of the existing problems and possible solutions with the application of water science and technology presented within the framework of efficient and sustainable engineering and management strategies.

We consider this holistic approach to be a unique aspect of this journal, and we look forward to close collaboration between our International Scientific Board and the scientific community in order to achieve this goal. Applied Water Science is a fully funded open access journal, and we sincerely thank the King Abdulaziz City of Science and Technology (KACST) in Saudi Arabia for sponsoring this venture. Their aim is to encourage the rapid development of water science and related technologies to achieve a future of plentiful fresh water in the Kingdom of Saudi Arabia, throughout the Middle East and indeed the world. Applied Water Science is therefore a completely open forum, free for all to read and to submit their papers to, providing maximum exposure for the science published in 
its pages and ensuring the rapid development of the journal and applied water science.

Welcome to Applied Water Science: Management and Infrastructure.
Open Access This article is distributed under the terms of the Creative Commons Attribution Noncommercial License which permits any noncommercial use, distribution, and reproduction in any medium, provided the original author(s) and source are credited. 